Journal of Engineering Sciences, Assiut University, Vol. 36, No. 3, pp.675-687, May 2008

\title{
SUPPLY CHAIN MANAGEMENT SIMULATION TYPES: A LITERATURE REVIEW
}

Mohammad Abd El-Aal

Demonstrator in Mechanical Engineering Department, Faculty of

Engineering, Assiut University, 71516 Assiut,

Mahmoud A. El-Sharief

Lecturer in Mechanical Engineering Department, Faculty of Engineering, Assiut University, 71516 Assiut,

\section{Ahmed Ezz El-Deen}

Assistant professor in Mechanical Engineering Department, Faculty of

Engineering, Assiut University, 71516 Assiut,

\section{Abo Bakr Nassr}

Professor in Mechanical Engineering Department, Faculty of Engineering, Assiut University, 71516 Assiut,

(Received February 27, 2008 Accepted March 22, 2008)

In today's global market, it becomes essential for supply chains to adapt powerful management policies. These policies might be verified and validated before its implementation in the real world. Simulation is a powerful effective tool for this purpose, so that, the last decade offered different supply chain simulation types. This paper is concerned with a review of supply chain management (SCM) simulation types in the recent researches. In particular, four SCM simulation types are reviewed, spreadsheet, system dynamics (SD), discrete-event dynamic systems (DEDS), and business games simulation types. The reviewed researches present great interest of SCM researchers in DEDS simulation among the four reviewed simulation types.

KEYWORDS: supply chain management (SCM); simulation; spreadsheet; system dynamics (SD); discrete event dynamic systems (DEDS); business games.

\section{INTRODUCTION}

Today's culture of the world has produced the term of globalization, which opens the markets for foreign producers. The most common markets competitive drivers are time and service, which refer to responsiveness and flexibility. The national economy of many of developed countries, rather than developing countries, is composed of small companies. Small and Medium sized Enterprises (SMEs) face many challenges due to its small size, limited resources, limited markets, and limited management experiences, and as a result they can't survive alone, so they can collaborate together to face its increased competition.

Supply chain (SC) structure is one of the most common and effective collaboration forms among SMEs. SC is defined as a cycle that starts and finishes in 
the costumer, through which raw materials are converted into final products (or services), then delivered to customers. SC is a network of suppliers, manufacturers, distributors, and retailers, that act together to control, manage and improve the over all SC performance. At its highest level, a SC is comprised of two basic, integrated processes: (i) the Production Planning and Inventory Control Process, and (ii) the Distribution and Logistics Process $[3,5,11,22,33]$.

SCs face numerous forms of risks during its design and operations. Some of $\mathrm{SC}$ risks forms are [16]:

- Uncertainties in Supply and Demand,

- Shorter product and technology life cycles,

- Increased use of Manufacturing, Distribution and Logistics service partners leading to longer and global supply chains,

- Essential to understand risks vs. customers and suppliers,

- Financial risks pertaining to excess or mismatched inventory, rework costs and non-delivery penalties.

For overcoming these risks some technology tools are performed to improve the SC performance. Among these tools, and the most common one, is the Supply Chain Management (SCM) technique. SCM involves the planning and management of material, information and financial flows in a network consisting of manufacturers, distributors, vendors and customers with the objective to reduce operating costs and improve customer service [10].

To implement SCM technique the critical performance measures of SCs must be clearly identified. SCM incorporates the use of analysis tools such as system dynamics, optimization, and simulation. Theoretical models of the SC behavior can be created by observing the SC's historical data or by collecting new data. Experiments that study the SC behavior are useful in order to find causal effects and to test different or even extreme scenarios. Causal effects are, however, difficult to find if they are separated in time and space and extreme scenarios are hard to control in a SC. An alternative to conducting experiments in the actual system is of course to use a model of the system for experimentation. Many of the SC models found in the literature are models used for optimization; Persson, and Araldi [30], provided an extensive work about SC optimization models. These models answer questions about plant location, product mix, choice of technology, distribution methods, inventory planning and control, choice of vendors, configuration, and reverse logistics. Optimization models consider the SC at specific instances in time and do not take on a dynamic view, as is the case with simulation models.

Optimization models often lack an estimation of the variability or robustness of a solution in a stochastic environment. Metrics such as lead-time variability, percentage of on-time delivery and so on, are hard to obtain when using an optimization model. In a literature review, Goetschalckx et al. [21], examine seven different modeling approaches for global logistics systems using mathematical programming. Only one model in the review utilized stochastic lead times and only a few included other stochastic characteristics. Stochastic characteristics are an important factor of supply chains. Especially, a stochastic demand is regarded as having great impact on financial performance.

There is a methodological and practical difference in the way optimization and simulation finds optimal solutions. In optimization, the solution is dependant on the 
scenario that defines the experimental domain. The optimal solution is only valid for that scenario and the solution will become invalid if the scenario changes. In simulation, it is possible to experiment with a set of different scenarios in order to find an optimal solution. The solution from simulation can therefore be made more insensitive for environmental changes as the optimal solution obtained through optimization. Simulation in SCM can offer a complement to the more prevailing modeling using optimization models, since simulation is more suited for representing random effects used for simulation-based optimization and predicting the dynamic behavior of SCs.

It is now clear that the most effective and efficient tool for measuring and stating the SC performance is the simulation modeling. The term simulation is used in different ways by different people. Simulation may be used to managing the SC and simulation can be defined as the process of creating a model (i.e., an abstract representation or facsimile) of an existing or proposed system (e.g., a project, a business, a mine, a watershed, a forest, the organs in your body) in order to identify and understand those factors which control the system and/or predict the future behavior of the system. Almost any system which can be quantitatively described using equations and/or rules can be simulated. The underlying purpose of simulation is to shed light on the underlying mechanisms that control the behavior of a system. More practically, simulation can be used to predict the way in which the system will evolve and respond to its surroundings, so that, it can identify any necessary changes that will help make the system perform the requirements [24].

The last few decades showed a great interest in simulation modeling of SCs. Many different types for SCs' simulation modeling were developed. Literatures distinguish four types of SCM simulation types [26]:

- Spreadsheet simulation,

- System dynamics (SD) simulation,

- Discrete-event dynamic systems (DEDS) simulation,

- Business games simulation

Spreadsheet-based analysis is mainly a static-deterministic approach and it can be reviewed as an automation of calculations based on SC data in order to analyze SCs [15].

System dynamics is a tool specifically suited for situations in which the evolution of the behavior of the system needs to be studied on an aggregate level over long time horizons [17].

Discrete-event dynamic systems simulation is the modeling of a system as it evolves over time by a representation in which the state variables change instantaneously at separate points in time. These points in time are the ones at which an event occurs, where an event is defined as an instantaneous occurrence that may change the state of the system $[\mathbf{9}, \mathbf{1 2}, \mathbf{2 7}]$.

A simulation game is a mixed feature of a game-competition, co-operation, participants and rules. Clearly these games take place on a simulated environment. They also confirm that simulation games can be utilized for several purposes, but are mainly utilized for educational purpose [14].

The first section of this paper provides a review of literature in the area of SCM simulation types and the rest of this paper offers a review for the different researches in the recent years that associated to the four SCs management simulation 
types that are mentioned above. Finally, a discussion about the differences between these types will be developed.

\section{SCM SIMULATION TYPES}

A simulation study consists of several steps such as data collection, coding and verification, model validation, experimental design, output data analysis, and implementation. Simulation modeling is a common paradigm for analyzing complex systems. A simulation model calls for executing a simulation program to produce sample histories. A set of statistics computed from these histories is then used to form performance measures of interest. Simulation is a powerful and important tool because it provides a way in which alternative designs, plans and/or policies can be evaluated without having to experiment on a real system, which may be prohibitively costly, time-consuming, or simply impractical to do [24]. The most common technical advantages of simulation techniques are its ability to [19]:

- Compress time, expand time,

- Control sources of variation,

- Avoid errors in measurement,

- Stop and review,

- Restore system state,

- Facilitates replication,

- Control level of detail.

Although simulation has many advantages, there are also some disadvantages of which the simulation practitioner should be aware of. These disadvantages are not really directly associated with the modeling and analysis of a system but rather with the expectations associated with simulation projects. These disadvantages include the following [13]:

- Simulation cannot give accurate results when the input data are inaccurate,

- Simulation cannot provide easy answers to complex problems,

- Simulation cannot solve problems by itself.

The following subsections introduce the four SCM simulation types, which mentioned in the previous section and the differences between them besides a review of the work done over the recent years that associated to these SCM simulation types.

\subsection{Spreadsheet Simulation}

Spreadsheet simulation may be considered the simplest and most broadly used in general purpose simulator. Although, Spreadsheets are inherently limited by their structure in many ways (e.g., representing complex dynamic processes is difficult, they cannot display the model structure graphically, and they require special add-ins to represent uncertainty), the spreadsheets are very widely used for simple simulation projects (particularly in the business world) [23]. 
Abu-Taieh and El Sheikh [1], investigated 56 packages, with the aim of tackling the trends that simulation packages are pursuing, and to address the issues denoting technology prevail. They found that, there are 15 packages, almost $27 \%$, that made a recommendation to use the spreadsheet or Microsoft

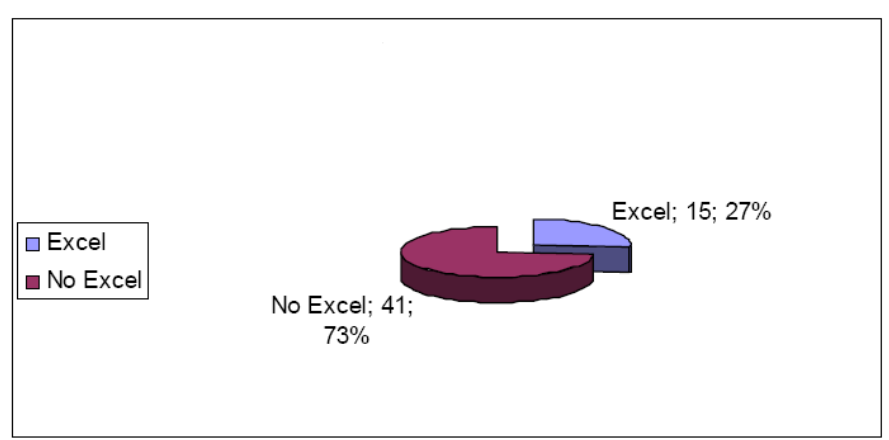

Figure 1: Excel usage in simulation packages

Excel as reporting tool. They emphasized on the significance of using spreadsheets in respect to the simulation packages, as seen in Figure 1. They also mentioned the fact that, spreadsheets alone are inadequate for assessing the probability of an event because they lack the ability to generate and analyze alternative scenarios in a sophisticated way.

Adams et al. [2], developed some approaches for combining hands-on simulation with spreadsheets and discrete event simulations aiming at enhancing the learning process of SCM principles. They used Microsoft Excel program as a spreadsheets simulation tool and a simulation software package called Extend as a discrete event simulation tool in order to simulate the two common simulation activities Just-In-Time (JIT), and the Beer Game simulations. They obtained two opportunities: animations for discrete event simulations, and randomness for the spreadsheets simulations.

Chwif et al. [15], compared two distinct simulation approaches for one of the largest aluminum processing companies in Brazil. The first approach configuration was built by using Excel Spreadsheet, while for the Discrete Event Simulation approach a SC simulator "SC Guru" version 1 was used. They obtained the two following conclusions:

- The effect of considering variation in some parameters of the SC like transportation times could not interfere significantly in the results of the chain. In this case both analysis methods would give equivalents results;

- The variation in demand plays a key role in the performance of the chain. Hence, in this case, any SC analysis should be performed by means of simulation; otherwise the static analysis from spreadsheets could show misleading results.

Boute and Lambrecht [8], presented a spreadsheet application to dealing with the largest two problems of SCs; the bullwhip effect and customer service. The presented spreadsheet application explores a series of replenishment policies and forecasting techniques under different demand patterns. Their proposed model followed the standard setup of the Beer Distribution Game. They showed how controlling the parameters of the replenishment policy induces or reduces the bullwhip effect. They also demonstrated how bullwhip reduction (order variability dampening) may have an adverse impact on inventory holdings. They clarify that order smoothing may increase inventory fluctuations resulting in poorer customer service. The spreadsheets can be used as an educational tool to gain a clear insight into the use of 
inventory control policies and improper forecasting in relation to the bullwhip effect and customer service.

Sezen and Kitapçi [35], developed a sample spreadsheet simulation model to illustrate the procedure of generating a simulation tool for the SC inventory allocation problem for a single distribution channel by using Monte Carlo simulation. It is simulated for three different scenarios reflecting various levels of demand fluctuations (high, medium and low demand variance). They claimed that the proposed modeling approach has potential value to the operational managers because it provides a simple methodology that can be implemented with any spreadsheet program, and that they presented several avenues for the use of spreadsheets in modeling SC systems. They mentioned that spreadsheets can be effectively used in modeling and simulation of SC inventory problems and also larger SC systems could be simulated using the same approach.

\subsection{System Dynamics (SD) Simulation}

$\mathrm{SD}$ is a continuous simulation approach which allows the quantities of interest, or state variables, to change continuously as time progresses, it is also concerned with the overall (aggregate and trend) system behavior under the influence of policies and is not greatly concerned with fine details [43].

Sabry and Beamon [33], developed an integrated multi-objective SC model for use in simultaneous strategic and operational SC planning. They adopted a decision analysis to their multi-objective SC model to allow use of a performance measurement system that includes cost, customer service levels (fill rates), and flexibility (volume or delivery). Their adopted performance measurement system provides more comprehensive measurement of SC system performance than do traditional singlemeasure approaches. Their developed model incorporates production, delivery, and demand uncertainty, and provides a multi-objective performance vector for the entire SC network.

Suwanruji and Enns [37], developed an approach that allows both delivery performance and inventory levels to be considered over a range of tradeoffs. They developed tradeoff curves and analyzed the area under each one. The developed approach can be especially useful when comparing different planning and control strategies, such as those using Distribution Requirements Planning (DRP), reorder point and Kanban ${ }^{1}$ systems. They also showed that their analysis approach is applicable where factors take on more than two levels.

Wilson [45], applied SD simulation in order to investigate how a transportation disruption affects the SC performance of a traditional SC and a vendor managed inventory (VMI) system when a transportation disruption occurs between 2 echelons in a 5-echelon SC.

\footnotetext{
${ }^{1}$ Japanese term for one of the primary tools of a just-in-time system. It maintains an orderly and efficient flow of materials throughout the entire manufacturing process. It is usually a printed card that contains specific information such as part name, description and quantity.
} 
S. Blanc et al. [32], presented the problems of interoperability ${ }^{2}$ and heterogeneity (which is non-interoperability) and some solutions have been detailed. For these solutions, which are mainly based on enterprise modeling techniques, they focused on semantic (which works on the signification of speech, i.e. the meaning of words and sentences) and organizational (which is related to the enterprise practices and then to enterprise modeling research works) heterogeneity. They presented the use of the appropriate performance measurement system to manage the evolution of the enterprises towards interoperability, i.e. the implementation and exploitation of the exposed principles.

Vlachos et al. [41], used the SD simulation technique to analyze the behavior of reverse SCs. The simulation model provides an experimental tool, which can be used to evaluate alternative long-term capacity planning policies ("what-if" analysis) using total SC profit as measure of policy effectiveness.

\subsection{Discrete-Event Dynamic System (DEDS) Simulation}

This simulation type relies on a transaction-flow approach to modeling systems. Discrete simulators are generally designed for simulating processes such as call centers, factory operations, and shipping facilities in which the material or information, that is being simulated, can be described as moving in discrete steps or packets. They are not meant to model the movement of continuous material (e.g., water) or represent continuous systems that are represented by differential equations [23].

Vieira [40], Vieira and Junior [39], and Wang and Takakuwa [44], used a discrete event simulation with ARENA simulation software to develop a module-based modeling method to analyze different types of SCs. The developed simulation model consisted of three hierarchical levels structured SC. The first level showed the interaction between the SC tiers like suppliers, manufacturers, retailers and consumer market and the flows in the chain (material and information flow). While in the second level each of those was refined to its main processes and procedures. The third level detailed some of the manufacturer's functions (intra-company) like the ordering and the fabrication procedure or sales $\&$ demand processes. The proposed method is used to analyze the performance of SCs. A number of outputs can be used as a performance measure in the decision making; the following performance measures were identified:

- Inventory holding cost.

- Shortage cost. The shortage cost is imposed when the stockout occurs at retailer.

- Transportation cost.

- Inventory level.

- Fill rate for the retailer echelon if it adopts lost sales. It is a customer service measure.

- Backorder fraction. Backorder fraction is also a customer service measure.

${ }^{2}$ The ability of two or more systems or components to exchange information and to use the information that has been exchanged. 
- The real lead time. Except for the transportation time between two facilities, the replenishment order lead time also includes the waiting time for shipment consolidation and order fulfillment.

- Cycle time between retailer and manufacturer.

- Variation on the production or order levels at the supplier's site.

Sarjoughian et al. [34], presented a hybrid modeling approach using DiscreteEvent and Model Predictive Control (MPC) ${ }^{3}$ enabled by a Knowledge Interchange Broker (KIB). This environment used the KIB to compose discrete event simulation and model predictive control models. This approach supported transparent and systematic specification of interactions between process dynamics and control decisions without relying on any single modeling paradigm.

Siprelle et al. [36], created a model represented the SC of a nationwide food production and distribution network, the developed model is studying alternative inventory allocations in a network. Their proposed SC is a company that produces thousands of product lines and is searching for the optimum allocation strategies for inventory to distribution centers to avoid cross-shipments of product. The simulation tool used is a discrete event model, developed by using Supply Chain Builder (which is an extension of Extend, a general purpose simulation package) from Simulation Dynamics, Inc. Their work described the data needs and logic of the used simulation tool along with its effectiveness in comparing strategies for locating consumer demand for finished goods (SKUs) inventory in a SC.

Dalal et al. [18], provided an overview of integration between a SC simulation model (VinLogic, which is designed to predict future network performance and status; this includes transit times; railcar, truck and facility utilization; bottlenecks, etc.) and a vehicle shipment information system (VinVision). A simulation model of DaimlerChrysler distribution network was built. The model is implemented in Simulation Dynamic's Supply Chain Builder product.

Lee and Umeda [28], specified a prototype system of a SC simulation, with the aim of supporting the users to make strategic decisions for improving the performance of the SCs. The authors also presented an information model that provides a framework of communication data in the prototype SC simulation. The developed SC simulation model is used to validate interface specifications as part of the Intelligent Manufacturing Systems (IMS) Modeling and Simulation Environments for Design, Planning and Operation of Globally Distributed Enterprises (MISSION) project.

Arbulu et al. [4], presented process models and discrete-event simulation results that characterize the design phase in the SC of pipe supports used in power plants. The models used to study how production system design factors such as batching, uncertainty, and multi-tasking throughout this phase affect SC performance. The authors illustrated two different simulation scenarios; the first simulation scenario is a deterministic model with batching which illustrates the contribution of batching to lead time. While the second simulation scenario is a probabilistic model for illustrating the impact of batching combined with variability and multitasking on lead time.

3 An approach for planning is aimed at tactical control concerned with short term (daily to several weeks) decision making. 
Jain et al. [25], presented a case study of using simulation models of the As-Is and the proposed To-Be processes for analyzing the impact of proposed changes in the SC processes for a large logistics operation and for the evaluation and comparison of their performance. The approach used integrated modeling of material, business processes, and communication flows to capture all aspects of the proposed changes.

Gan et al. [20], illustrated how distributed simulation can be used to realize model encapsulation (i.e. using distributed simulation techniques to eliminate the obstacle that many participating companies are not willing to share detailed model information when the chain crosses the enterprise boundaries). Each enterprise can create its own detailed simulation to facilitate the process of supply chain design, evaluation and optimization.

\subsection{Business Games Simulation}

A game can be defined as a clearly defined activity with its own roles and incentives, carried out for its own purpose. A simulation game combines simulation and gaming. This implies that the roles and incentives of the game simulated some real-world phenomenon. Simulation gaming is not usually carried out for its own purpose but to train the participants in decision-making in a role similar to one in the real world [29]. The simulation game shows the building up and reinforcing processes of fluctuations of demands within SCs [6]. The purposes of games, regardless of their origin, are the same and can be classified as [31]:

- Promoting knowledge and skill,

- Increasing behavioral skill,

- Giving pleasure and promoting teamwork.

Ritchie-Dunham et al. [32], described a simulation game designed to quantify the benefits of an Enterprise Resource Planning (ERP) coupled with the Balanced Scorecard Framework (BSF) in an extended enterprise. The designed simulation game quantifying five major benefits of ERP and BSF: systems integration, data and process standardization, visibility across the business enterprise, improved decision support functionality, and operational strategy. The authors considered three scenarios of the enterprise, the organization pre-ERP implementation, the improved organization after an ERP implementation, and the benefits inherent in the ERP implementation (i.e., integration, standardization, and, functionality).

Van Houten et al. [38], presented the distributor game, which was the first of a series of management games developed for today's SC challenges such as globalization, increasing importance of the customer role and mass customization. The distributor game was based on an architecture suitable for providing games for many different problem contexts and scenarios, in a distributed, web-enabled setting.

Wang and Fong [42], described the development and implementation of a real-life SC game for industrial engineering students aims at helping them to gain hands-on experiences in managing demand, supply and inventory in a SC.

Zhou et al. [46], proposed two-echelon SC models based on game theory, composed by a manufacturer in the upstream and a retailer in the downstream. That SC is assumed to be operated in a fuzzy environment which is associated with the customer's demand and the manufacturing cost. They considered two different game structures of SC: the manufacturer and the retailer cooperate with each other and 
behave as an integrated-firm; the manufacturer behaving as a Stackelberg ${ }^{4}$ leader dominates the SC.

\section{CONCLUSION}

This research was concerned with a review of SCM simulation types in recent researches. These reviewed researches illustrated the importance of applying simulation for different policies of SCM, and it also presented how these types differed from each other. In our review research we focused on four SCM simulation types; spreadsheet, system dynamics (SD), discrete event dynamic systems (DEDS), and business games. Spreadsheet SCM simulation is too simple and for some what unrealistic. SD simulation for SCM policies is concerned with the overall behavior of the SC (e.g. bullwhip effect) with an aggregated or qualitative view. DEDS simulation is more detailed than SD simulation in representing individual events and incorporating uncertainties to $\mathrm{SC}$ simulation models. It provides quantitative indications about the SC performance. Business games simulate real SC environment for education and training purposes, since the players are active participants in the simulated world. The reviewed researches present great interest of SCM researchers in DEDS simulation among the four reviewed simulation types.

\section{REFERENCES}

[1]. Abu-Taieh, E.M.O. and El Sheikh, A.A., "Commercial simulation packages: a comparative study", International Journal of Simulation, Vol. 8 No. 2, Pp. 66-76, 2007. http://ducati.doc.ntu.ac.uk/uksim/journal/Vol-8/No-2/paper-7.pdf.

[2]. Adams, J., Flatto, J. and Gardner, L., "Combining hands-on, spreadsheet and discrete event simulation to teach supply chain management", In Proceedings of the 2005 Winter Simulation Conference, Pp. 2329-2337, 2005.

[3]. Altiok, T. and Melamed, B., "Simulation modeling and analysis with arena", Textbook, Academic Press, New York, USA, Pp. 263, 2007.

[4]. Arbulu, R.J., Tommelein, I.D., Walsh, K.D. and Hershauer, J.C., "Contributors to lead time in construction supply chains: case of pipe supports used in power plants", In Proceedings of the 2002 Winter Simulation Conference, Pp. 1745-1751., 2002

[5]. Beamon, B.M, "Supply Chain Design and Analysis: Models and Methods", International Journal of Production Economics, Vol. 55, No. 3, Pp. 281-294., 1998.

[6]. Bickel, S., Yildiz, M., Blessing, B. Kriz, W.C., Olsowski, G. and Eiselen, T., "eBeerGame - an online simulation game for the training of supply chain management", ISAGA, 2007.

http://www.isaga2007.nl/uploads/final\%20papers/p02-def.pdf

${ }^{4}$ The Stackelberg leadership model is a strategic game in economics in which the leader firm moves first and then the follower firms move sequentially. 
[7]. Blanc et, S., Ducq, Y. and Vallespir B., "Evolution management towards interoperable supply chains using performance measurement", Computers in Industry, No. 58, Pp 720-732, 2007.

[8]. Boute, R.N., and Lambrecht, M.R., "Exploring the bullwhip effect by means of spreadsheet simulation", Vlerick Leuven Gent Management School, 2007.

[9]. Braubach, L., Pokahr, A., Lamersdorf, W., Krempels, K.-H. and Woelk, P.O., "A Generic Simulation Service for Distributed Multi-Agent Systems", Cybernetics and Systems, Pp. 576-581, 2004. http://vsis-www.informatik.unihamburg.de/getDoc.php/publications/197/timeservice.pdf

[10]. Caputo, A.C., Pelagagge, P.M., Scacchia, F., "Integrating transport systems in supply chain management software tool", Industrial Management \& Data Systems, Vol. 103, No. 7, Pp. 503-515, 2003.

[11]. Carvalho, H., and Machado, V. C., "Management decision making under uncertainty in the Supply Chain", IIE Annual Conference, 2005.

http://xenofonte.demi.fct.unl.pt/unidemi/Papers/hc_vcm_IERC05.pdf

[12]. Cassandras, C.G. and Lafortune, S., "Introduction to Discrete Event Systems", Textbook, $2^{\text {nd }}$ ed., Springer Science+Business Media, LLC, New York, Pp. 48, 2008.

[13]. Chung, C.A, "Simulation modeling handbook: a practical approach", Textbook, CRC Press LLC, Florida, 2004.

[14]. Chwif, L. and Barretto, M.R.P, "Simulation models as an aid for the teaching and learning process in operations management", In Proceedings of the 2003 Winter Simulation Conference, Pp. 1994-2000., 2003.

[15]. Chwif, L., Barretto, M.R.P., and Saliby, E, "Supply chain analysis: spreadsheet or simulation?", In Proceedings of the 2002 Winter Simulation Conference, Pp. 59-66., 2002.

[16]. CLM ROUNDTABLE INDIA, "Harnessing value in supply chain”, 2004.

http://www.cscmpindia.com/Events/17022004/2.PDF

[17]. Collaboration Support Technologies \& System Dynamics In Strategic Niche Management: Providing The Navigational Deck, 2007.

http://www.mech.upatras.gr/ nikos/colltech/work_fall06/06_03-

Papachristos.pdf

[18]. Dalal, M.A., Bell, H., Denzien, M. and Keller, M.P, "Initializing a distribution supply chain simulation with live data", In Proceedings of the 2003 Winter Simulation Conference, Pp.1621-1626., 2003.

[19]. Fishman, G., "Discrete-Event Simulation: Modeling, Programming, and Analysis", Textbook, Pp. 26-27, 2001.

[20]. Gan, B.P., Liu, L., Jain, S., Turner, S.J., Cai, W. and Hsu, WJ, "Distributed supply chain simulation across enterprise boundaries", In Proceedings of the 2000 Winter Simulation Conference, Pp. 1245-1251, 2000.

[21]. Goetschalckx, M., Vidal, C.J. and Dogan, K., "Modeling and design of global logistics systems: A review of integrated strategic and tactical models and design algorithms", European Journal of Operational Research, Vol. 143, Pp. 1-18, 2002.

[22]. Herrmann, J.W., Lin, E. and Pundoor, G., " Supply chain simulation modeling using the supply chain operations reference model", In Proceedings 
of DETC'03 ASME 2003 Design Engineering Technical Conferences and Computers and Information in Engineering Conference, 2003.

[23]. http://www.goldsim.com/Content.asp?PageID=456, "Types of simulation tools".

[24]. http://www.goldsim.com/Content.asp?PageID=91, "What is simulation".

[25]. Jain, S., Ervin, E.C., Lathrop, A.P., Workman, R.W. and Collins, L.M, "Analyzing the supply chain for a large logistics operation using simulation", In Proceedings of the 2001 Winter Simulation Conference, Pp. 1123-1128., 2001.

[26]. Kleijnen, J.PC. and Smits, M.T., "Performance metrics in supply chain management", Journal of the Operational Research Society, Pp.1-8, 2003.

[27]. Krenn, B. Engelhardt-Nowitzki, C. Savu-Krohn, C. and Zsifkovits, H., "Building Models of Global Supply Chains (Basic Principles and Requirements)", 2007.

http://personal.unileoben.ac.at/csavukrohn/nofoma2007.pdf

[28]. Lee, Y.T. and Umeda, S., "An IDEF1x Information Model for a Supply Chain Simulation", Proceedings of the 7th International Conference on Manufacturing, Pp 291-296, 2002.

http://www.mel.nist.gov/msidlibrary/doc/idefx.pdf

[29]. Meijer, S. and Hofstede, G.J., "Simulations and Simulation Games in Agro and Health Care", 2004.

http://library.wur.nl/wasp/bestanden/LUWPUBRD 00324763 A502 001.pdf

[30]. Persson, F. and Araldi, M., "The development of a dynamic supply chain analysis tool-Integration of SCOR and discrete event simulation", International Journal of Production Economics, 2007

[31]. Raghavan, N.R.S., Shreshtha, B.B. and Rajeev, S.V., "Object Oriented Design and implementation of A Web-enabled Beer Game for Illustrating the Bullwhip Effect in Supply Chains", International Journal of Technology Management, Vol. 28, No.2 Pp. 191-205, 2004.

[32]. Ritchie-Dunham, J., Morrice, D.J., Scott, J., and Anderson, E.G., "A strategic supply chain simulation model", In Proceedings of the 2000 Winter Simulation Conference, Pp.1260-1264, 2000.

[33]. Sabri, E.H. and Beamon, B.M., "A Multi-Objective Approach to Simultaneous Strategic and Operational Planning in Supply Chain Design", OMEGA, Vol. 28, No. 5, Pp. 581-598, 2000.

[34]. Sarjoughian, H.S., Huang, D., Wang, W., Rivera, D.E., Kempf, K.G., Godding, G.W. and Mittelmann, H.D., "Hybrid discrete event simulation with model predictive control for semiconductor supply chain manufacturing", in Proceedings of the 2005 Winter Simulation Conference, Pp. 256-266, 2005.

[35]. Sezen, B. and Kitapçi, H., "Spreadsheet simulation for the supply chain Inventory problem", Production Planning and Control, Vol. 18, No. 1, Pp. 9-15, 2007.

[36]. Siprelle, A.J., Parsons, D.J. and Clark, R.J., "Benefits of using a supply chain simulation tool to study inventory allocation", In Proceedings of the 2003 Winter Simulation Conference, Pp. 238-245, 2003.

[37]. Suwanruji, P., and Enns, S.T., "Evaluating the performance of supply chain simulations with tradeoffs between multiple objectives", In Proceedings of the 2004 Winter Simulation Conference, Pp. 1399-1403, 2004. 
[38]. van Houten, SP.A., Verbraeck, A., Boyson, S. and Corsi, T., "Training for today's supply chains: an introduction to the distributor game", In Proceedings of the 2005 Winter Simulation Conference, Pp. 2338-2345, 2005.

[39]. Vieira, G.E. and Junior, O.C., "A conceptual model for the creation of supply chain simulation models", In Proceedings of the 2005 Winter Simulation Conference, Pp. 2619-2627, 2005.

[40]. Vieira, G.E., "Ideas for modeling and simulation of supply chains with arena", In Proceedings of the 2004 Winter Simulation Conference, Pp.1418-1427, 2004.

[41]. Vlachos, D., Georgiadis, P. and Iakovou, E., "A system dynamics model for dynamic capacity planning of remanufacturing in closed-loop supply chains", Computers \& Operations Research, No. 34, Pp. 367-394, 2007.

[42]. Wang, J. and Fong, Y.C., "A Real-Life Supply Chain Game to Enhance Problem Based Learning for Industrial Engineering Students", International Conference on Engineering Education - ICEE 2007, 2007.

http://icee2007.dei.uc.pt/proceedings/papers/561.pdf

[43]. Wang, J., "A System Dynamics Simulation Model for a Four-rank Military Workforce", Land Operations Division, DSTO Defense Science and Technology Organization, 2007.

[44]. Wang, X. and Takakuwa, S., "Module-based modeling of productiondistribution systems considering shipment consolidation", In Proceedings of the 2006 Winter Simulation Conference, Pp. 1477-1484, 2006.

[45]. Wilson, M.C.," The impact of transportation disruptions on supply chain performance", Transportation Research Part E, No. 43, Pp295-320, 2007.

[46]. Zhou, C., Zhao, R., Tang, W., "Two-echelon Supply Chain Games in a Fuzzy Environment", Computers \& Industrial Engineering, 2008.

\section{أسالب محاكاة الأنظمة الإداريـة لسلاسل الإمداد: مراجعة}

أدى انتشار الأسواق العالمية إلى لجوء سلاسل الإمداد المكونـة من الثركات الصغيرة والمتوسطة لتغبير إسـتراتيجياتها فى الإدارة والإنتـاج حتى تواكب إسـتراتيجيات الإدارة والإنتاج الحديثة. وقبـل تتفيذ نلك الإستراتيجيات يجب أن يتم مراجعتها للتحقق والتأكد من قابليتها للتتفيذ على أرض الواقع. لذا تعد برامج المحاكاة وسيلة قوية وفعالة لتطبيق تلك الإستراتيجيات قبل التتفيذ. فى خلال العقد الأخير من الزمن تم تطبيق أسـاليب متعددة لمحاكاة الأنواع المختلفة مـن سلاسـل الإمداد. يركز هذا البحث على مراجعة الأسـاليب المختلفة للمحاكاة المستخدمة فى إدارة سلاسل الإمداد وذلك من خـلال تقديم أربعة أسـاليب


الأحداث المتقطعة و ألعاب الأعمال. يعرض هذا البحث لمجوعة كبيرة من الأبحاث الحديثة التى نتاولت أساليب المحاكاة المختلفة. وكانت نتيجة البحث أن أكثرالأسـاليب إستخدماً و فعاليةً لمحاكاة أنظمة إدارة سلاسل الإمداد هو أسلوب الأنظمة الديناميكية ذات الأحداث المتقطعة. 